\title{
Complexity and Simplification in Language Shift
}

\author{
Jessica Kantarovich ${ }^{1,2 *}$, Lenore A. Grenoble ${ }^{1,2}$, Antonina Vinokurova $^{2}$ and Elena Nesterova ${ }^{3}$ \\ ${ }^{1}$ Department of Linguistics, University of Chicago, Chicago, IL, United States, ${ }^{2}$ The Arctic Linguistic Ecology Lab, North-Eastern \\ Federal University, Yakutsk, Russia, ${ }^{3}$ The Institute for Humanities Research and Indigenous Studies of the North (Siberian Branch \\ of the Russian Academy of Sciences), Yakutsk, Russia
}

This paper examines the question of linguistic complexity in two shift ecologies in northeastern Russia. It is frequently claimed that language shift results in linguistic simplification across a range of domains in the grammars of shifting speakers (Campbell and Muntzel 1989; Dorian 1989; O'Shannessy 2011). We challenge the breadth of this claim, showing that while there are undoubtedly patterns that can be described as a simplification of some grammatical domain, the overall grammars of these speakers cannot be said to be "simple," as simplification in one part of the grammar often corresponds to complexification in other parts ("complexity trade-offs"). Furthermore, patterns that are deemed loss or simplification are often presented in such a way because they are being compared to earlier varieties of the shifting languages; however, such patterns are entirely typologically expected, are consistent with other languages of the world, and can be seen as more or less complex depending on one's locus of measurement. In this paper, we present incipient changes taking place in Chukchi (Chukotko-Kamchatkan, ISO ckt) and Even (Tungusic, ISO eve) stemming from the modern language shift context. We evaluate these changes against different notions of complexity to demonstrate that a more nuanced approach to morphosyntactic change in language obsolescence is warranted. While morphological simplification is expected in these scenarios, other changes in these speakers' systems (occurring as potential adaptations in light of simplification) provide a more enlightening avenue for research on shifting varieties.

Keywords: language shift, word order, case marking, agreement, noun incorporation, Chukchi, Even, language contact

\section{INTRODUCTION}

In this paper we examine the question of linguistic complexity in two shift ecologies in northeastern Russia. It is frequently claimed that language shift results in linguistic simplification across a range of domains in the grammars of shifting speakers (Campbell and Muntzel 1989; Dorian 1989; O'Shannessy 2011). This paper joins a growing group of voices in challenging the breadth of this claim, showing that while there are undoubtedly patterns that can be described as a simplification of some grammatical domains, the overall grammars of these speakers cannot be said to be simple, as simplification in one part of the grammar often corresponds to complexification in other parts ("complexity trade-offs"). Furthermore, patterns that are deemed loss or simplification are often presented in such a way because they are being compared to pre-shift documentation of the language in question; however, such patterns are entirely typologically expected, are consistent with 
other languages of the world, and can be seen as more or less complex depending on one's theoretical framework. Similar arguments have been made with regard to other languages in the context of language shift; for example, Meakins and Pensalfini (2016) point to systematic, rule-governed variation and optionality in the superclassing system of gender and number marking in Jingulu. Van den Bos et al. (2017) provide the example of the emergence of a relative case system (i.e., a syncretism between possessor and transitive subject marking) in Gurundji Kriol for some children. Meakins et al. (2019) argue a very similar position as the present paper: that in the case of innovation in Gurundji Kriol, there is no evidence that speakers of this mixed variety show a preference for the adoption of the less complex of two variants, where complexity is calculated according to a variety of parameters including the number of free morphemes and the degree of redundant morphological marking.

This paper turns instead to claims about simplification in unstable, rapidly evolving scenarios of language shift, in which variation and change have seldom been systematically and neutrally documented. We report on two understudied languages in contact with Russian: Chukchi (iso 639-3 ckt, Chukotko-Kamchatkan) and Even (iso 639-3 eve, Tungusic), which are spoken in northeastern Russia. Speakers of these languages are shifting to Russian as their primary language; the extent of shift is somewhat more pronounced in Chukchi than Even, which a small number of children living in remote villages are still learning as a first language. Still, language shift is widespread for both language communities, and younger generations of speakers of both languages display morphological and syntactic deviations from the conservative varieties used by older speakers, often in similar ways. In this study, we consulted speakers across different age groups and acquisition backgrounds and asked them to participate in a series of controlled production tasks, in order to derive comparable utterances and narratives across different speakers of each individual language.

We find, first of all, that speakers of all degrees of proficiency in the endangered language use it systematically. While shifting speakers may differ from their conservative counterparts and from one another, individual speakers display the same grammatical patterns across different stimuli and study tasks, even when they are interviewed on separate occasions, suggesting that these speakers have more stable idiolects than previously thought. ${ }^{1}$ In other words, these speakers make use of rule-ordered systems, like those of any robustly-spoken language-the major way that these varieties differ from robustly-spoken ones is that they are not conventionalized and show a high degree of interspeaker variation.

Broadly speaking, it is indeed the case that shifting speakers of both languages evidence some type of morphological

${ }^{1}$ One Chukchi speaker consulted in this study, for example, made use of the same innovative pattern of object agreement marking discussed in section 3.2.1 when providing paradigms in two elicitation sessions which took place 1 year apart. This same speaker also employs this innovative agreement marking regularly in freelygiven utterances in conversation and narratives. reduction in a strict numerical sense: they make use of a smaller range of inflectional and derivational morphemes. In certain cases, speakers appear to lack a particular morphological category entirely, e.g., some Chukchi speakers no longer make use of a number of spatial cases and in Even some speakers do not use any converbs. In other cases, only the exponents of that category have been reduced; for example, there is increased syncretism in the object agreement markers in the Chukchi verbal complex, but the agreement slots themselves are preserved. In other areas, such as derivational morphology, Chukchi speakers also show a decrease in the productivity of certain morphemes, such as voice and valency markers.

This shrinkage of options is consistent with changes reported by previous scholars of these varieties, such as Campbell and Muntzel's (1989) claims of "stylistic shrinkage" and the reduction of morphological and syntactic resources, and Sasse's (2001) observations that language shift tends to produce morphological leveling, a move from agglutination/ polysynthesis to isolation, and replacement of "complex" synthetic constructions by analytic ones. However, while there is a reduction in the number of distinct morphological forms in our target languages, it is not clear that the resulting patterns are actually "simpler" in either a numeric or cognitive sense. In these languages, morphological simplification results in the existence of relatively rigid rules governing the distribution of the forms that remain and about which speakers have strong, prescriptive judgments-the addition of these more arbitrary rules is arguably in itself a kind of complexity.

There are other phenomena in the speech of shifting Chukchi and Even speakers that challenge the simplification narrative. Both languages display instances of complexity trade-offs between different grammatical domains, such as the morphology and syntax. In Chukchi, there is a move from encoding arguments through verbal morphology to the use of separate nominals, which otherwise obey standard syntactic rules in the language (a reduction in the degree of synthesis, also observed in other heritage varieties though seldom analyzed as a kind of resultant syntactic complexity, see Polinsky, 2018). In Even, we can observe the relatively well-studied trade-off between the use of case-marking to indicate the grammatical role of arguments vs. a more rigid word order (Sinnemäki, 2014), a pattern that has been observed in other shift varieties, such as Young People's Dyirbal, where rigid word order was innovated at the expense of ergative-absolutive case marking (Schmidt, 1985). Standard Even has both core case marking and rigid SOV word order, and we find that both experienced and shifting speakers exhibit a trade-off in resolving the redundancy of this system: proficient speakers preserve case marking but not word order, while shifting speakers preserve word order but not necessarily case marking (much like the Dyirbal case).

By using parallel production tasks across different languages that are in contact with Russian, the current paper builds a broad empirical base to evaluate the complexity of grammars in shifting speakers. To the best of our knowledge, there has been no other such systematic application of the same experimental tasks across different languages within the same contact ecology. This paper 
illustrates just one way that such an approach is fruitful: it enables us to evaluate the effects of language shift and contact on similar grammatical phenomena in unrelated languages that are otherwise experiencing the same sociolinguistic pressures while in contact with the same language (in this case, Russian).

Our preliminary findings reveal the different ways that a shifting language could be complex in its own right and we offer ways of analyzing this complexity. Thus, this paper addresses theoretical questions about the relationship between language shift and linguistic complexity and offers a methodology for the examination of the typological status of shifting linguistic systems, without recourse to what they lack relative to robust systems.

\subsection{Complexity}

The notion of complexity is often invoked offhand in comparative discussions of languages or linguistic features, without a firm theoretical or typological grounding. However, what makes a particular pattern more or less complex relative to another is anything but straightforward: more or less complex according to whose frame of reference? Is there such a thing as "absolute" complexity in language and, if so, how do we calibrate or quantify this complexity? Such questions have been considered at length in the theoretical literature on complexity, but these issues have not always been given the attention they deserve in linguistic work that bases important assumptions on notions such as "complexification" and "simplification," notably, the literature on language contact and shift.

\subsubsection{Is Language Shift a Process of Structural Simplification or Reduction?}

Although there is no broad consensus on how to define complexity across languages, this has not prevented most scholars working with endangered varieties from describing them as simplified versions of their proficiently-spoken or more conservative counterparts. The same is true of other varieties resulting from contact, such as pidgins and creoles: the prevalent assumption is that these varieties are necessarily simplified relative to monolingual systems. These arguments are often made in conjunction with claims about the increased cognitive load of juggling multiple linguistic codes (Muysken, $2000,41)$ or the deficient input associated with the settings that give rise to mixed varieties such as pidgins and creoles. Claims about the low complexity of contact varieties have been particularly strong in the literature on creoles, which are fullfledged languages (unlike basic communicative systems like pidgins) but are claimed by some to be universally simpler than any non-creole system (McWhorter, 2001; Plag, 2003; Bakker et al., 2013; Blasi et al., 2017). Here too, other scholars have objected to such categorical claims: Good (2012), for example, argues for a difference between paradigmatic simplicity and syntagmatic complexity in creoles (a trade-off we also note here), and Klein (2012) demonstrates that creoles can and do have complex phonemic inventories, countering claims advanced by Trudgill (2011).

In-depth studies of obsolescing languages (that is, endangered languages without proficient speakers, or as used by less- proficient "semi-speakers" or "heritage speakers") are not as abundant as the work on creoles, but the research that has been done reflects a tendency to focus on the simplification that occurs in obsolescence, especially in the morphology. In these cases, "simplification" typically refers to a quantitative reduction in the number of distinct forms (a reduction in allomorphy or contrastive elements, e.g., paradigmatic leveling) or the elimination of certain morphemes altogether (e.g., the loss of a morphological slot for person, number, tense, aspect, etc.). However, it is important to note that this is merely one way of analyzing (or one dimension of) the grammatical patterns of these speakers, and it results from a particular ontology set by the researcher, in which all "semi-speaker" language use is defined by virtue of not being as "complete" as that of fluent speakers and where it is therefore interesting to isolate what is missing from these varieties compared to their conservative counterparts. In her discussion of the status of semi-speakers, Dorian (1977, 23-4) notes Mary Haas' assumption that "any language which continues to be spoken by only a very few people will exhibit a much reduced form as compared with the same language in vigorous use by a rich linguistic community." Claims of this nature demonstrate the a priori assumption that the loss of linguistic complexity should follow from a literal reduction in the frequency of language use, which promotes a certain interpretation of semi-speaker differences.

In her own work, Dorian (1981) analyzes language maintenance on a continuum, asking questions about the relative proficiency of East Sutherland Gaelic speakers across different generations. This framing of the question-i.e., to what extent do less proficient speakers deviate from the "correct" East Sutherland Gaelic patterns-naturally conditions the presentation of the results, in which Dorian tallies the number of "correct" responses from different speaker groups. In the domain of morphological inflection (of nouns and verbs), the semi-speakers have difficulty inflecting those tenses and genders where the class of the stem is not overtly indicated by multiple linguistic signals (such as both phonological lenition and an overt inflectional suffix). For example, semi-speakers show decreased retention of patterns such as gender-appropriate adjective lenition, in which attributive adjectives are expected to be lenited after feminine nouns but are unaffected following masculine nouns (Dorian, 1981, 127-8). The pattern among semi-speakers can be described as loss of gender encoding through lenition, as semi-speakers in Dorian's sample did not lenite adjectives appropriately for the corresponding gender and actually showed a slight tendency to lenite in the presence of a masculine noun. Thus, the pattern can be seen as a kind of simplification or streamlining of gender-marking, where adjective lenition is no longer a meaningful gender signal. However, as Dorian herself notes, the nature of this change in terms of the overall encoding of gender is complicated (Dorian, 1981, 146-7): not all strategies for encoding gender are lost to the same extent, and in fact the most generalizable (and arguably the "least complex") rule of adjective lenition is the one that is lost. Thus, it is premature to say that the overall resulting system of gender encoding of semi-speakers is less complex, especially as more than half of the semi-speakers retain other less-productive 
ways of marking gender (e.g., the use of gendered diminutive suffixes).

\subsubsection{Theories of Complexity and Complexity Trade-offs}

As we can see, even the case of East Sutherland Gaelic-a foundational example of "language decay"-is not a straightforward example of the loss of complexity due to language shift. Like most authors who invoke "complexity," Dorian takes for granted that it is obvious how the ESG gender system is complex. We can extrapolate from the discussion that in this case, complexity refers to the fact that there are multiple ways of signaling gender in this system, not all of which apply to every possible construction, some of them having a degree of optionality even for older fluent speakers. This idea aligns with the oft-invoked Kolmogorov complexity, where the complexity of a linguistic pattern is the shortest possible length of its description (Sinnemäki, 2014; Mufwene et al., 2017). While this may be the best metric available to us, description length will nevertheless depend on which aspects one chooses to zero in on (as determined by one's theoretical framework) as well as the frame of reference (who is the observer and how does his/ her existing linguistic knowledge mold the description), and can thus be difficult to compare across studies.

Ultimately, even absolutist theories that try to find a uniform means of measuring complexity acknowledge that all languages are equally expressive, and must therefore reflect complexity of thought somewhere in the grammar. (See Kusters, 2008; Miestamo, 2008 for further discussion.) In fact, we usually encounter a "trading relationship between the different parts of the grammar" in terms of their complexity (Aitchison, 1991). Complexity is necessarily constrained by the locus and unit of measurement, and we must be careful when considering attriting, shifting, and other non-normative varieties that we do not focus on simplification to the exclusion of all the other unique features of these varieties. Just as we see complexity trade-offs between different levels of the grammar in robustlyspoken languages (Siewierska, 1998; Koplenig et al., 2017), so too do we expect a loss of complexity in one grammatical level to be offset by another in shifting varieties, which continue to be viable languages.

There have been a variety of proposals that strive to rigorously codify competing types of complexity within a single grammar (e.g., Dahl, 2004; de Groot, 2008). Here, we primarily engage with the one offered by Audring (2016) for grammatical gender, as it is especially fruitful for considering different dimensions of complexity in inflectional morphology and syntactic relations. While Audring identifies at least 5 competing domains where complexity can be expressed in grammatical gender, here we only concern ourselves with the three principles Audring uses to calibrate complexity within each domain:

- Principle of Economy: the greater the number of distinctions or forms associated with a feature, the more complex the feature

- Principle of Transparency: a one-to-one mapping between meaning and form is the least complex
- Principle of Independence: in the least complex case, a single feature is independent of other grammatical features and grammatical domains

This framework illustrates why it is difficult to arrive at a uniform categorization of a single language's grammatical system (or a subpart of that system like gender) as complex or not: for example, is a language like English less complex because it displays gender in fewer forms (only pronouns), or is a language like Dutch less complex because gender is an inherent property of all nouns?

Considering these different domains where complexity has been studied, it is clear that most studies of contact varieties and endangered languages that focus on simplification limit themselves to the morphophonological domain and measure individual morphemes, alternations, or rules. We do not deny that, in these cases, within these domains and relative to the language prior to the onset of contact or shift, there are instances of simplification: a literal reduction of rules and/or forms. However, simplification in inflectional morphology is far from the only dimension of linguistic complexity that is worth considering in shifting varieties. As the East Sutherland Gaelic example has already shown and as we demonstrate in Chukchi and Even, a reduction in inflectional morphology is not the only, and certainly not the most noteworthy, pattern of change in the shift context. In the following sections, we do not advocate for a new approach to calibrating complexity or else promote one existing approach over another; rather, we show that shifting varieties are only simpler than their predecessors in the basic quantitative sense of having "less" morphology. If we evaluate shifting speakers' grammatical systems as a whole, rather than focusing on individual parameters, trade-offs between different grammatical domains become readily apparent.

\section{MATERIALS AND METHODS}

This study combines a mixed methods approach to the study of language change and shift. In conjunction with traditional linguistic fieldwork, including elicitation of constructions and acceptability judgments together with recordings of spontaneous conversation and narratives, we have implemented a series of controlled tasks. The present article is based on findings from traditional elicitation and from experiments of two types: 1) picture production experiments (PPE): targeted elicitation using pictures and lexical prompts (one series of 14 pictures, another series of 27); and 2) focused narrative elicitation: narration based on controlled video and picture stimuli. The goal of these tasks was to gather a maximally comparable sample of constructions from speakers of different backgrounds, in order to look for qualitative linguistic differences between the speaker groups. In general, we report in-depth findings for small groups of speakers or even individual speakers, and note broad patterns where appropriate. Higher-level statistical analysis of the results is not possible at this time, given the dearth of participants. Nonetheless, great care has been taken by the researchers to target the same morphosyntactic phenomena with a variety of 
approaches, and even anecdotal data is important to note for future research, given how little has been published about the current state of these languages and how difficult they are for most researchers to access.

\subsection{Participants and Recruitment}

Research was conducted in 2017, 2018 and 2019 with researchers speaking to respondents in Russian or in one of the target languages (Chukchi or Even). Recruiting and execution of this study were approved by the Institutional Review Board of the University of Chicago. Participants gave verbal assent to be recorded and were asked whether they preferred to be identified by name or by a pseudonym. They were allowed to end the experiment at any time. A number of participants opted out of some of the experiments because they found them too difficult to complete; these are discussed in the relevant sections. Participants were welcome to discuss their answers afterwards, and in many cases stayed with the researchers to discuss the state of their language and their own attitudes toward it. Conditions for running the experiments were more like those of traditional linguistic fieldwork (in private homes) than in laboratory settings. Participants were not given a time limit to complete any task; due to frequent interruptions and discussion of the tasks with the participants, response times are also not considered.

The target languages differ from one another genealogically and typologically but are spoken in communities with many similar social contexts and histories. Even (iso 639-3 eve, Tungusic) is an Indigenous minority language of the Republic of Sakha (Yakutia) where it enjoys official status as a local language in those places where the ethnic population is dense. In such pockets, including the villages Berezovka and Sebyan-Kyuyol, it is still learned by children in the home and is a language of everyday communication. Still, Even is undergoing rapid language shift, with an estimated 5656 speakers of 21,830 , or roughly $26 \%$ of the total ethnic population.

Chukchi (iso 639-3 ckt) is highly endangered: it is claimed as a language by 5,095 people out of an ethnic population of 15,908 (or about $32 \%$ ). Like Even, it enjoys official status within the Republic of Sakha (Yakutia), but oddly enough, not in the Chukotka Autonomous Okrug, where most ethnic Chukchi reside. Unlike Even, there are virtually no monolingual Chukchi speakers remaining and the language is not being transmitted to children, with the possible exception of some rural areas where reindeer herding is practiced. Figures for both languages are based on the most recent All-Russian Census of 2010 and are outdated. Numbers for both languages were also almost certainly inflated at the time of the census, and are all the more so now, given that some of the older fluent speakers have passed away in the intervening years. Furthermore, the census has shown continual decline in speakers since the post-World War II period.

Neither language serves as the language of broader communication on even a local level. In the case of Even, speakers in rural areas in the Republic of Sakha will also typically be proficient in the Sakha language; in more urban areas in the Republic, Even speakers typically use Russian as their primary language. Russian serves as the primary language for most Chukchi speakers throughout the Russian North. A separate written alphabet exists for both languages (Cyrillic, with added special characters for nonRussian phones). Some Chukchi and Even speakers received a formal (university) education in their native languages, where they learned to read and write using these alphabets; other speakers have at least attained a passive knowledge of how to parse the Even/Chukchi orthographies through what limited schooling in these languages was made available to them.

All speakers in our study are bilingual in the target language and Russian. Speakers provided self-assessments of their own language proficiency levels, ranging from novice to L1 speakers. Interviews were conducted in the target language or Russian, depending on the preference of the consultant and on the proficiency of the interviewer.

Potential participants who self-identify as ethnic Chukchi or Even were recruited by snowballing in different locations in the far northeastern regions of the Russian Federation, including two urban centers: 1) Anadyr, a town of 15,489 that serves as the regional capital of the Chukotka Autonomous Okrug; and 2) the city of Yakutsk, the capital of the Republic of Sakha (population 318,768). Additionally, people who self-identified as ethnic Even were recruited in the village of Berezovka (population est. 250), an Even-dominant village in the Srednekolymsk Region of the Republic of Sakha, and in the towns of Bilibino and Chersky (ChAO), each with populations somewhat over $5000 .^{2}$

Within each geographic region, speakers tend to be part of the same (or adjacent) social networks. Thus, we are not considering an entirely random sampling of ethnic Chukchi and Evens: we have necessarily selected for speakers who meet some base level of proficiency (e.g., they can read) and have sufficient interest in their ethnic language to engage in work with linguists. As a result, we do not consider two potentially interesting groups in this study: older speakers of varying degrees of proficiency who did not wish to work with the researchers (often, male members of the communities) and younger speakers who either could not or were too intimidated to participate in the controlled study tasks, but whose speech may also be of interest in future work.

\subsubsection{Chukchi Participants}

The Chukchi participants can be divided into the following groups, on the basis of proficiency and background in the language (acquisition, degree of education, etc.). Proficiency has been estimated based on speakers' own self-assessment as well as how they are regarded by others in the community. Distinguishing between conservative and shifting speakers is

${ }^{2}$ Population data for 2019, when the bulk of the data were collected, come from State Statistics Russia (https://rosstat.gov.ru/compendium/document/13282). 
fairly uncomplicated: conservative speakers have frequently attained higher education in Chukchi and may be involved in the creation of educational materials. They are those speakers who acquired the language at home and managed to avoid being sent to Russian-language boarding schools. Many of them continue to use the language in some capacity on a daily basis and they tend not to have difficulty recalling lexical items or describing everyday events (of the kind targeted by the study tasks). Perhaps contrary to expectations, there is a fair amount of overlap in age between the speaker groups. This is a result of the fact that linguistic proficiency among the Chukchi is more-closely linked to their acquisition backgrounds and whether their families were engaged in traditional cultural practices (such as reindeer herding and whaling), than to universal generational experiences. Nevertheless, the most conservative speakers are typically also the oldest speakers in their communities:

- Conservative speakers: comprises six speakers who ranged in age from their 50-70's at the time of data collection. Five speakers completed the 27-picture production experiment (PPE) and provided Bridge Story narratives. Three of these speakers also supplied Dog Stories. An additional 6th speaker participated in the 27PPE task, but produced a full narrative for each stimulus instead of a single sentence. His results are excluded from the experimental component of the study, but were examined as additional narratives.

- Shifting speakers: comprises the seven attriting speakers and heritage learners of Chukchi. The speakers range in age from 35 to 59, with four speakers in their 30's and 3 in their 50 's. All seven speakers completed the 27 PPE task and all but one speaker provided a Dog Story. 5 of the speakers provided Bridge Stories.

All but one speaker were recorded in Anadyr; the remaining speaker (a shifting speaker) was recorded in Yakutsk.

\subsubsection{Even Participants}

A total of 21 Even speakers were recorded. 14 completed a separate 14-picture production experiment, and 10 completed the 27PPE. Three speakers completed both tasks. Only those speakers who completed the 27PPE were asked to complete the Bridge Story task; 8 of the 10 did so. As with Chukchi, speaker groups were determined by proficiency and acquisition background.

Speakers were recorded in different settings: six speakers, all from Even-speaking villages, were recorded in Yakutsk where they currently reside. 11 speakers were recorded in Berezovka, an Even-dominant village; additional speakers were recorded in far northern villages: 3 in Bilibino and 1 in Chersky.

In general, more highly proficient speakers tend to be older, but more than age we see a correlation between proficiency levels and a rural/urban divide. Speakers raised in rural Even-dominant villages who have spent less time living in large cities are more

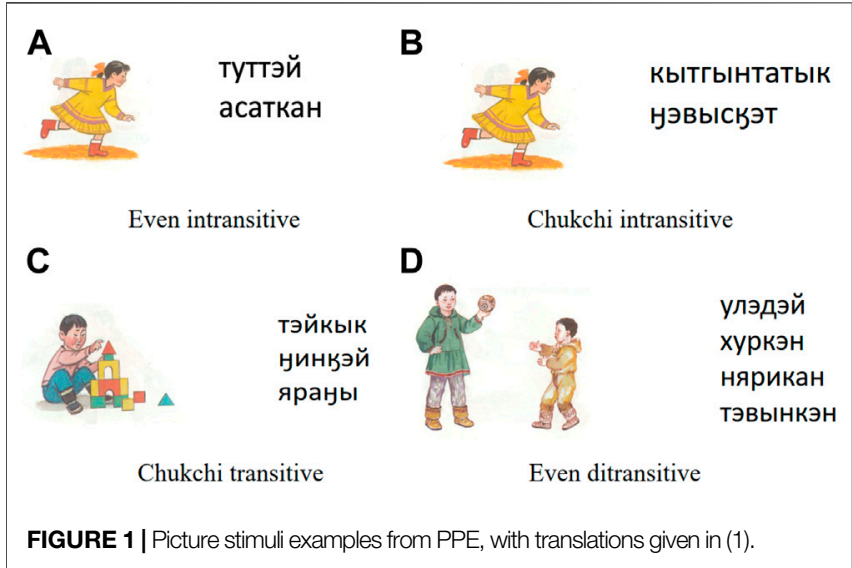

likely to be highly proficient; speakers who have spent significant time living in cities are more likely to show signs of shift and/or attrition. In our sample pool, all speakers in Yakutsk showed since of two of the more proficient speaker are women ages 20 and 21 .

- Conservative speakers: 14 speakers who ranged in age from 20 to mid 60's at the time of data collection. This includes all four speakers from Bilibino and Chersky and 1 of the younger university students living in Yakutsk at the time of recording (temporarily, in student housing) who maintains close ties to her home village. 2 of the older speakers recorded in Yakutsk maintain the language, speak it at home on a daily basis, and view Even as their first and primary language. This total also includes

- Shifting speakers: comprises seven attriting and shifting speakers, including 5 from Berezovka and two recorded in Yakutsk.

The numbers are skewed toward highly proficient, "conservative" speakers and suggest that language shift is less widespread in Even than is in fact the case. Rather, a number of shifting speakers declined to complete any of the tasks, including the 14PPE, which we assumed would be less intimidating because the lexicon is provided. In addition, it is important to note that the term "conservative" is somewhat misleading: all speakers tested showed Russian influence, and the older village speakers exhibited considerable code-mixing in the Bridge Story texts. Only the two university students did not code-mix in the Bridge Story narratives, perhaps precisely because they are students (and are used to being tested).

\subsection{Picture Production Experiments}

The study includes the results of two language production experiments, one consisting of 14 pictures (14PPE) and the other of 27 (27PPE). In each experiment, speakers were presented with slides containing one picture and a set of 
words in citation form, given in a vertical column, with the verb listed first. Speakers were asked to construct sentences that correspond to what they saw in the picture, using the lexicon provided (and only the lexicon provided). They were shown a single slide at a time, and the slide was displayed for as long as necessary for the speaker to produce a sentence or opt to skip the stimulus. The same pictures and roughly the same lexical items were used across languages, though they were presented in different orders. (Words were swapped out as needed for cultural or semantic reasons in the different languages; however, verbal valency and the semantic roles of the provided nouns were maintained for the same image across the two languages.) Critically, the order in which the pictures were displayed was random; the events and characters portrayed were unrelated and not connected to a larger context or overarching narrative. A sample of stimuli from the two languages is seen in Figure 1.

Figures 1A,B show the same picture with Even and Chukchi stimuli, respectively, targeting an intransitive verb. Figure 1C provides an example of a Chukchi transitive and Figure 1D of an Even ditransitive. Example (1) provides transliteration and English glosses for the stimuli in Figures 1A-D:

(1) Stimuli for Figure 1

\begin{tabular}{|c|c|c|c|c|c|c|}
\hline $1 \mathrm{~A}$ & 1B & & $1 \mathrm{C}$ & & 1D & \\
\hline Even & Chukchi & English & Chukchi & English & Even & English \\
\hline $\begin{array}{c}\text { tuttəj } \\
\text { asatkan }\end{array}$ & $\begin{array}{c}\text { kətgəntatək } \\
\text { jewəcqet }\end{array}$ & $\begin{array}{l}\text { 'run' } \\
\text { 'girl' }\end{array}$ & $\begin{array}{l}\text { tejkək } \\
\text { jinqej } \\
\text { jarayı }\end{array}$ & $\begin{array}{l}\text { 'build' } \\
\text { 'boy' } \\
\text { 'house' }\end{array}$ & $\begin{array}{c}\text { ulədəj } \\
\text { hurkən } \\
\text { narikan } \\
\text { təßynkən }\end{array}$ & $\begin{array}{l}\text { 'throw' } \\
\text { 'youth' } \\
\text { 'boy' } \\
\text { 'ball' }\end{array}$ \\
\hline
\end{tabular}

The task was designed to elicit sentences with a range of argument structures. We selected verbs of different valencies (intransitive, transitive, ditransitive) and argument combinations with different animacy values and semantic roles. The goal was to generate a sufficiently varied set of constructions in order to observe a range of case marked nominals, verbal inflection, and word orders. Example (2) contains the conditions associated with each picture stimulus. Ditransitive verbs are those where a third oblique argument is required for a grammatical utterance; 3-place intransitives are those where the verb takes an optional oblique argument but where an utterance would be grammatical without it.

The stimuli were provided in Cyrillic without any other information, as illustrated in Figure 1, so that speakers needed to recognize the meaning of each word to construct a sentence. At the same time, providing the lexicon not only constrained possible outcomes, but it made the task more achievable for speakers who felt unsure about their knowledge of grammar. (Some speakers who were able to complete this task could not complete other tasks where they needed to supply the lexicon themselves.) Each list of stimuli begins with the citation form of the verb (the impersonal form of the purposive converb in Even and infinitive in Chukchi), followed by the argument nouns, also in citation form (nominative in Even and absolutive in Chukchi). In Even, one of our goals was to discern basic word order. We hypothesized that any speaker would be unlikely to start a context-free sentence with a verb. And indeed, no Even speaker produced a V-initial utterance (with the exception of one picture set, where the speaker simply repeated the stimuli, but in this instance the speaker failed to produce a sentence). As there is no default word order in Chukchi, all possible orders were attested in this task. All responses were produced orally.

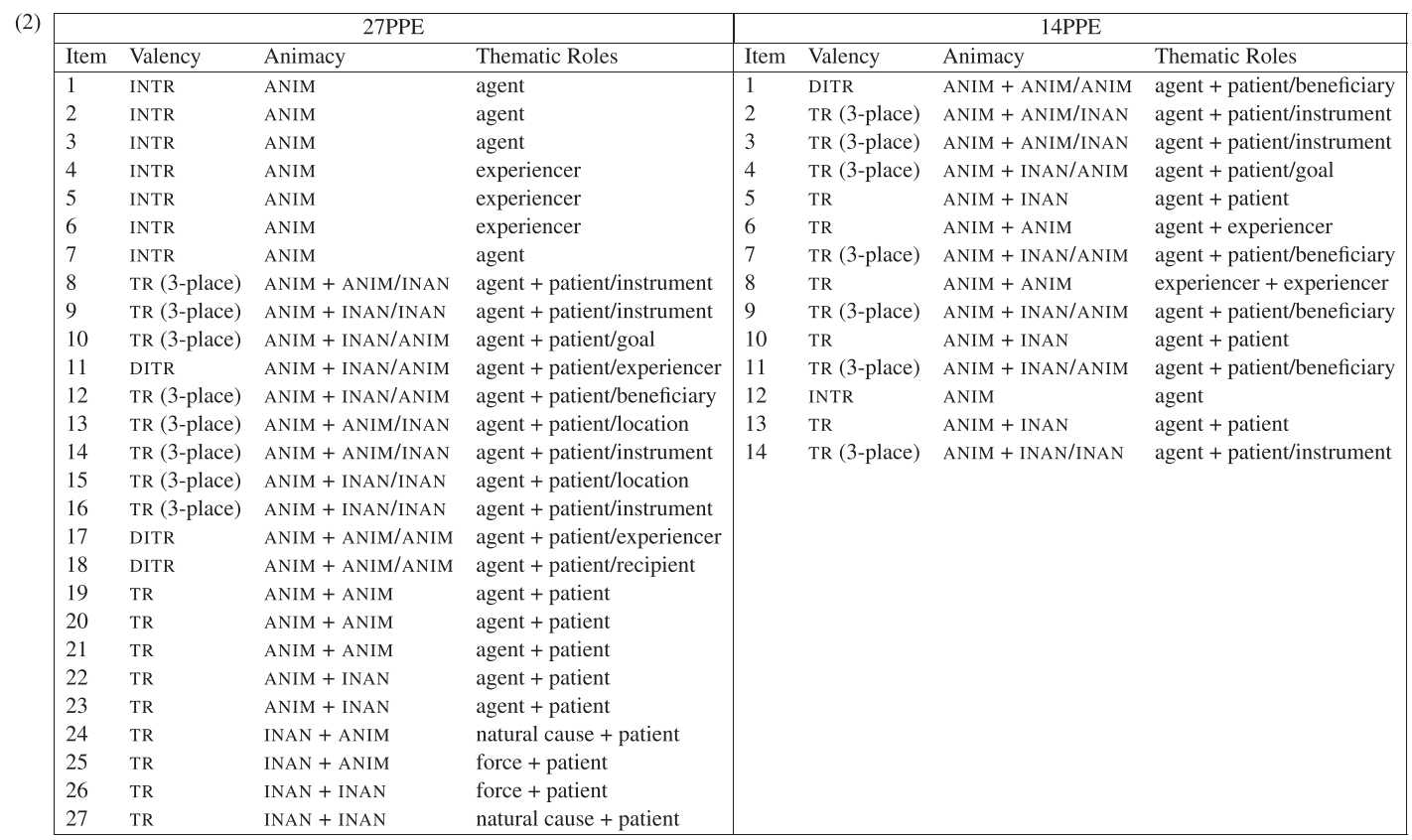




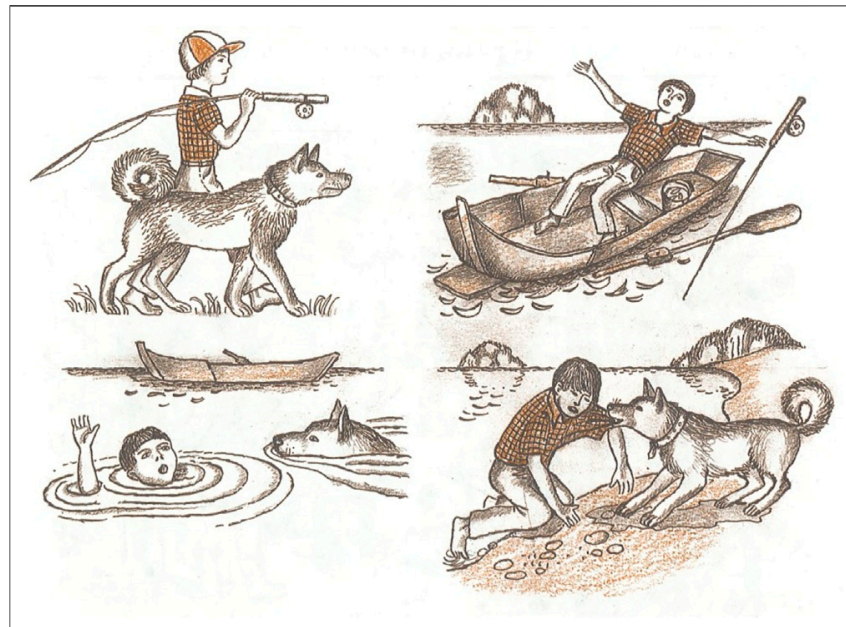

FIGURE 2 | Picture stimulus for Dog story task.

An expected response in Even for Figure $\mathbf{1 A}$ is given in example (3):

(3) asatkan- $\varnothing$ tut-tə- $n$

girl-NOM run-NFUT-3SG

'The girl runs.'

or, alternatively, with a change in aspect of the verb, with the nonpast imperfective in (4) [versus the simple non-past in (3)]:

(4) asatkan- $\emptyset$ tutə- $d-d \partial-n$

girl-NOM run-NFUT-IMPF-3SG

'The girl is running.

\subsubsection{Data Coding for PPE}

Although the PPE experiments in both languages targeted semantically similar sentences, the two languages differ morphosyntactically and the resulting data was coded for separate phenomena.

All results for the Even PPE were glossed according to Leipzig Glossing Conventions ${ }^{3}$, and coded for word order; for the present study we are focused on the position of the verb relative to other constituents. The results were transcribed by native speakers of the target language, with glossing and translation by teams of native speaker linguists and non-native specialists in the target languages. Word order was coded for Subject (S), Verb (V), and direct Object $(\mathrm{O} 1)$ and other oblique Object $(\mathrm{O} 2)$, where $\mathrm{O} 2$ included arguments other than the direct object, in the dative, instrumental or any of the spatial cases. Each sentence in the PPE experiment was assigned a single word order. In most cases, this was straightforward. A clear example is seen in (5), where the word order was coded as S-O2-O1-V:

(5) $\beta$ əj- $\varnothing \quad$ narikan-du olra- $\beta \quad$ bö- $\varnothing-n$

man-NOM boy-DAT fish-ACC give-NFUT-3SG

'The man gives the fish to the boy.'

Example (5) illustrates what we consider to be an expected response, with canonical word order and case marking. Across

${ }^{3}$ We use Leipzig Glossing conventions wherever possible, see Bickel et al., 2015. conservative speakers, we anticipated variation in the TAM form of the verb, and possible variation in the order of $\mathrm{O} 1$ and $\mathrm{O} 2$. Descriptions of traditional Even grammar show these to be interchangeable, with the order $\mathrm{O} 2-\mathrm{O} 1$ to be somewhat more frequent. At present we have insufficient data to determine whether there is a preferred order for objects that are preverbal.

Coding word order in the majority of responses was straightforward as speakers produced each word in the stimuli once. False starts were not coded if the speaker continued to correct the form, as in example (6).

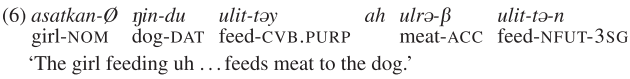

Here the word order was coded as $\mathrm{SO} 2 \mathrm{O} 1 \mathrm{~V}$; the first instance of the verb repeats the form in the stimulus (ulittry) which is followed by a clear hesitation, after which the speaker continues with the expected grammar and word order. This is treated as a false start and not counted in the word order.

Sometimes a speaker repeated a word form, which was counted only once, as in (7).

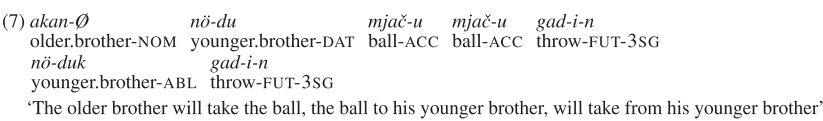

Example (7) illustrates a number of different characteristics of L2 Even, but here we note only that the word order was coded once as SOOV since, again, in the word order analysis we are interested in the position of the verb relative to other constituents. Here the speaker completes a clause with the verb in final position and then continues to correct the case marking on younger brother, changing it from the dative to the ablative. But in both instances the verb stands at the end.

In the Even 14PPE, one speaker for one picture only, repeated the stimuli, in the same forms and order as provided with the picture:

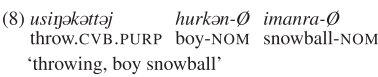

This was coded as VSO order, and this is the only order that this speaker produced for this prompt; in fact, 12 out of 14 of her utterances were well-formed $\mathrm{SO}(\mathrm{O}) \mathrm{V}$ sentences.

The Chukchi PPE results were transcribed and coded by one of the authors, who specializes in Chukchi. Given the distinct typological nature of Chukchi (a polysynthetic language with subject and object agreement, noun incorporation, and free word order), the results were coded differently from those in Even. The tokens were coded according to their deviation from the expected agreement marking in Standard Chukchi, whether there was any noun incorporation of any of the arguments (or use of any other valency-changing operations), and word order. The latter did not represent an interesting domain for investigation, as virtually all speakers, including shifting speakers, produced a variety of orders that did not correlate with study conditions.

The Chukchi data presented extreme idiolectal variation, as expected in a moribund language. In Chukchi, this issue is 
compounded by the existence of extreme regional lexical variation, so speakers frequently asked to substitute more appropriate words from their lexicon in place of the provided stimuli. Thus, overall, numerical generalizations about the recurrence of specific structures are not that enlightening, and the Chukchi data is subject to a more qualitative interspeaker comparison.

\subsection{Focused Narrative Elicitations}

We collected two sets of targeted narratives, the Dog Stories and the Bridge Stories. The Dog Stories were elicited using a 4-frame series of pictures that were printed on one page (Figure 2). This enabled the speaker to see the entire set of pictures at once and formulate a cohesive narrative. For the Bridge Story task, participants were asked to watch a short cartoon that depicts a bear and a moose trying to cross a narrow bridge (available at https://www.youtube.com/watch?v=_X_AfRk9F9w\&t=1s). The film is $2 \mathrm{~min}$ and $20 \mathrm{~s}$ long, with a simple storyline, making it easy to remember. It has just four animal characters: a moose, a bear, a raccoon and a rabbit; all but the raccoon are commonly found in the Russian North. The target languages both lack a native word for raccoon; speakers use the Russian word (enot 'raccoon' or barsuk 'badger') or a neologism (e.g., 'masked cat' or 'little animal'). In both tasks there were no linguistic cues: no words accompanied the pictures and the cartoon characters did not speak.

\section{RESULTS}

\subsection{Word Order and Case Marking in Even}

Conservative Even is a fixed head-final language, with SOV word order, in all sentence and clause types (e.g., declarative and interrogative sentences; matrix and subordinate clauses) (Malchukov, 1995, 19). However, linguists working in the context of minority linguistic communities in the Russian Federation have reported a move to SVO in head-final languages for decades, attributing the changes to Russian contact influence (for Tungusic see Rishes 1947; Grenoble 2000; Malchukov 2003). In order to assess their impressionistic accounts, we analyze Even word order in context-free sentences produced in tightly-controlled elements (the 14PPE and the 27PPE), and in the more open-ended narrative production tasks.

Standard Even (Malchukov, 1995) and the Berezovka dialect (Robbek, 1989) spoken by a number of our participants have rich case morphology with 14 cases, including a relatively extensive set of spatial-locative cases. Only the nominative case has a zero morpheme; all other cases are signaled by an overt suffix. Some of the spatial cases are used infrequently and do not occur in our data. The PPE data show the nominative, accusative, dative, instrumental cases, and a few tokens with ablative and allative (generally instead of an expected dative). The Bridge Story data exhibits use of the prolative and robust usage of relational nouns for spatial relations.

We find that shifting Even speakers are by no means using a straightforwardly "simpler" system; rather we find less proficient speakers mostly rigidly adhering to $\mathrm{V}$-final structure but omitting inflectional morphology (even though their own responses in the task indicate that they have some command of it). In contrast, the more proficient speakers exhibit word order changes and syntactic restructuring but maintain the case system to signal grammatical roles in some speakers, and rigid V-final word order and either lack of case morphology or deviations from expected cases in other speakers. Several patterns emerge across shifting speakers: 1) dropping the accusative and dative case suffixes in some sentences, using no nominal inflectional morphology; 2) overextension of the instrumental or allative cases (instead of an expected dative), and more generally using cases inconsistently and differently than in the standard language; and 3) uncertainty about which case to use, as evidenced by their using a stimulus in one case, then repeating it in another, until they make a decision.

\subsubsection{Word Order Changes in Even Picture Production Experiments}

All Even speakers in this study have received some education in the standard language and are literate, and thus could be expected to know word order in the standard language. Our working hypothesis was that we would find word order changes in Even under Russian influence, independent of speaker proficiency, from rigid V-final order to more flexible SVO order on a Russian model, where word order is relatively flexible and discourse-driven. We predicted that the Picture Production Experiments would be more likely to elicit V-final order than the Bridge Story: by supplying the lexicon, we allowed for more planning time for production, and the speakers did not need to recall a narrative plot or any details. The narrative tasks were considerably less constrained, lexically and structurally, although participants did need to recall and use certain core lexical items corresponding to the characters and settings involved, such as 'moose', 'bear', 'raccoon', 'rabbit', and 'bridge'. Word order was coded for every utterance in each task.

A pattern emerges that correlates relative proficiency in the target language with word order changes, with less proficient and shifting speakers more likely to adhere to rigid V-final order, and more proficient speakers less likely to follow prescriptive norms. Moreover, speakers who exhibit word order changes maintain nominal inflectional morphology. Shifting speakers who struggled to produce some sentences maintained rigid V-final order but dropped case morphology (although they did produce them in other sentences).

This can be illustrated by a closer look at the responses of the 14 Even speakers who completed the 14PPE. Of them, only half produced all sentences with $\mathrm{V}$-final order. There is considerable variation across speakers as to how many $\mathrm{VO}$ sentences they produced. One speaker in Berezovka produces no V-final clauses, and one in Yakutsk produces only 6. Both speakers use full inflectional morphology, showing no loss of case marking. From a complexity trade-off standpoint, there is no reason to expect the maintenance of both rigid word order and case marking. Thus, although rigid word order is "lost," the result mirrors trade-offs that exist in robustly-spoken languages. In other words, changes to less rigid head-final word order correlate with a maintenance of inflectional morphology.

The numbers here would possibly be higher except that a number of speakers simplified the target sentences and omitted arguments. In the 14PPE, 12 of the 14 stimuli include ditransitive verbs, so that we would anticipate that traditional Even speakers would produce 12 sentences SOOV and 2 SOV. Half of the 
sentences with an object after the verb are of the SOVO type, while half are SVOO.

Several sentences were more likely than others not to be V-final, and these stimuli also produced challenges for the shifting speakers. The shifting speakers exhibiting difficulty in forming sentences with ditransitive verbs in both the 14PPE and the 27PPE, and difficulties in forming sentences with unfamiliar lexical items (or those with lower frequency). Such difficulties are signaled by hesitations in production, repetition of the stimuli, and self-correction. Two strategies for resolving these challenges are dropping arguments, or dropping case inflection. In particular accusative marking is dropped, notably for those stimuli that require 3 arguments.

For example, Picture 10 depicts a girl asking a boy for the doll which he is pictured as holding in his hand. However, the stimuli words do not include the boy, given in example (9):

P10 Stimuli: gasčidaj asatkan bajkan 'ask.CVB.PURP girl.NOM doll.NOM'

(9) asatkan- $\varnothing \quad$ bəjkə-m gasč- $\emptyset$-in

$\begin{array}{lll}\text { asatkan- } \emptyset & \text { bəjkə- } m & \text { gasč- } \emptyset \text { - } i n \\ \text { woman-NOM } & \text { doll-ACC } & \text { ask-PRS-3S }\end{array}$

'The girl asks for the doll'

More confident speakers simply added an a rgument to match what they saw in the picture, but there was great variation as to what case was used here: instrumental, ablative and locative all occur. Two speakers misinterpreted the word bejkan 'doll' $(<b e j$ 'man', 'person') as referring to an animate human and made it the subject of the sentence, as in (10):

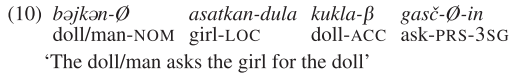

P4 presented considerable difficulties, and two speakers rearranged the stimuli without using any inflectional morphology, as in (11):

P4 Stimuli: gadaj mjač akan nö 'take.CVB.PURP ball.NOM older.brother.NOM younger.brother.NOM'

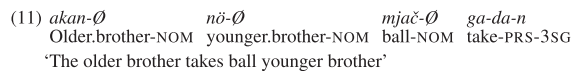

As illustrated in (14), one strategy by some speakers is to drop the second oblique argument, as in example (12) from the same set of stimuli, where the noun akan 'older.brother' is simply omitted:

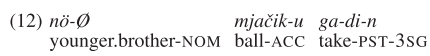

This strategy simplifies the target sentence to make it easier for the speaker to produce. Although the production experiments were designed to prohibit this kind of simplification, it is a strategy that speakers followed. Other stimuli that elicited syntactic simplification were those aimed at the production of converb constructions (P6 to teach X to cook'), which some speakers converted to two finite clauses.

Picture 11 depicts a woman making tea with a small girl standing nearby watching. We expected the version in (13) but two speakers dropped an argument, as in (14):
P11 Stimuli: iri-t-taj čaj asi asatkan 'make.CVB.PURP tea.NOM woman.NOM girl.NOM'

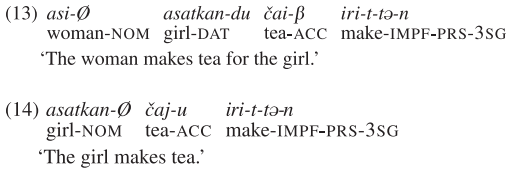

Example (14) further illustrates a difference in the usage of morphology between conservative and shifting speakers: the more conservative speakers use the accusative suffix $-\beta$, where others use what could be the Berezovka dialect variant $-u$, but is homophonous with the Russian partitive genitive, which is frequently used with this word in such contexts. Only three speakers used the suffix $-\beta$, versus 9 who used the form $\check{c} a j u$; one speaker incorporated it into a verb form. (Note that the noun mjač 'ball' is a borrowing from Russian, and in (12) it appears with the Russian diminutive suffix-ik. 4 of the 14 speakers did not mark this noun in the accusative case, although five did add the Even accusative $-u$, as in (12), and 2 used the instrumental case).

Finally, these examples demonstrate the challenges of quantifying the responses numerically. In a very basic way, the fact that speakers dropped an argument in the production of sentences with ditransitive/ 3-place transitive verbs changed the number of words in the resulting sentences which, in turn, almost certainly had an impact on word order; in the Bridge Story narratives we find that the direct object is more likely to precede the verb than an oblique argument or a conjunct. More specifically, in the Bridge Story narratives, postverbal elements are likely to be NPs in a spatial case, signaling source, goal, or location, relational nouns, or a spatial adverbial.

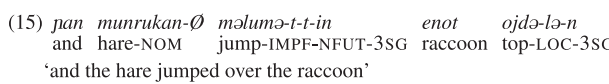

In the Bridge Stories, the two speakers with most rigid V-final order were also the youngest, both coming from villages where Even is spoken but recorded in Yakutsk while studying at the university. One declared Even to be her first, primary language and the other felt that she was more proficient in Russian. Each produced only one sentence where an object followed the verb; in both cases it was a spatial argument (mosta-duk bridge-ABL 'off the bridge'). The Bridge Story narratives of the two university students are striking not only in terms of the near $100 \%$ adherence to V-final structure, but also in lack of code-mixing, simple syntax, and clauses conjoined with conjunctions. One speaker begins all but two sentences with a conjunction or adverbial connector (e.g., nan 'and'; temi 'therefore'; tačin 'thus', and tarit 'then', which begins six sentences). The other begins 3 clauses with tarit 'then' and 2 with nan 'and'. Their narratives are short: the six other speakers used 23-25 finite clauses, while each of these speakers uses only 13 finite clauses. The Bridge Stories, unlike the PPE sentences, showed high levels of code-mixing for some speakers, and information structure encoded in word order, except for these two younger speakers.

Lastly, it is worth noting that shifting speakers show changes in syntactic strategies for clause combining. They are less likely to use non- 
finite verb forms and are more likely to combine multiple finite clauses, paratactically or with conjunctions, without embedding.

Note that no Even speakers without any core case marking were recorded, but this does not mean that they do not exist. Rather, they opted out of the tasks. Their lack of participation is more a reflection of the way speakerhood is interpreted in the context of the Russian Federation, where less-proficient L2 speakers are stigmatized and discouraged from attempting to speak by other members of the community.

Let us consider, however, whether these shift-induced strategies are in any way more or less complex than conservative Even. SVO and SOV are arguably equally cognitively-taxing from a processing standpoint; in fact, typologically-speaking, SOV is actually a more common rigid order in the world's languages than SVO (Dryer, 2013). There is some evidence that SOV might actually be favored, as it is the preferred order in emergent sign languages and ad hoc gesturing, due to cognitive biases. (For an overview and references, see Gibson et al., 2019, 396-7.) Either way, it would seem that a loss of inflectional morphology (simplification) creates a trade-off favoring fixed word order (complexification); meanwhile, for other speakers, maintenance of inflectional morphology represents the preservation of complexity, that is required by the change to more flexible word order.

Alternately, a preference for SVO may indeed be an example of simplification. In an experimental study that focuses specifically on the position of finite verbs in German, Weyerts et al. (2002) find that it is easier to process sentences with the finite verb in second position, immediately following the subject, than sentences with the finite verb in final position. Interestingly, this preference even holds for embedded clauses which require the finite verbs to be in clausefinal position in German. If this is mapped onto Even, then the use of SVO order facilitates processing; the shift from SOV to SVO could be correlated with maintenance of inflectional morphology to facilitate $\mathrm{S}$ and $\mathrm{O}$ disambiguation and avoid cognitive overload (see Hawkins, 2004 for a discussion of efficiency in cognition). Thus, if this is a kind of simplification due to processing issues, it is a normal process that stems from cognitive limitations on all language processing, not from the shift situation ("language decay") specifically.

The production findings have several interesting implications for issues of complexity and loss under language shift. With respect to the latter, the majority of speakers in this group maintain the V-final rule to some extent but show extensive variation in case marking, including a complete lack of case morphology in some sentences. As the Bridge Stories show, even the proficient speakers do not produce rigidly V-final order $100 \%$ of the time, so the shifting speakers are potentially expanding a pattern that already exists in the language. At any rate, our findings provide experimental confirmation that there is not a straightforward switch from V-final to SVO order.

Furthermore, it is not clear that the pattern used by shifting speakers is simpler: is the use of variable orders less complex than the use of a single rigid order? From the standpoint of descriptive complexity, it may actually be the reverse: the description of variable word orders used in different contexts is longer (and therefore more complex, from a Kolmogorov perspective) than a single universally-applied order.

\subsection{Morphosyntax of Modern Chukchi}

Although Chukchi is a relatively understudied language, there are several grammatical domains that have been especially wellresearched by linguists, including verbal inflection and (to a lesser extent) verbal derivational morphology (Skorik 1948; Nedjalkov 1977; Polinskaja and Nedjalkov 1987; Polinskaja 1991; Spencer 1996; Bobaljik 1998, inter alia). As Chukchi is a polysynthetic language, the verb is the locus of much of the information encoding of the sentence: it conveys not only the lexical verb (what is being done) but also its tense, aspect, and mood, and both the subject and object through agreement marking or noun incorporation. A simplified version of the verbal template is given in (16):

(16) Agreement/Mood-Tense-(Voice $o r$ Incorporation)-Stem-(Voice)-Aspect-Agreement

Material in parentheses is not obligatory (these slots mainly indicate valency-changing operations, discussed in section 3.2.2). The two agreement slots, though obligatory, differ in terms of which argument features they encode (subject or object, person and/or number) depending on the tense and transitivity of the verb. The agreement prefix slot consistently encodes the subject in both transitive and intransitive verbs, and is fused with mood (i.e., there are different forms of the agreement prefix for the same person/number combination in different moods). The suffix slot agrees with either the object (in transitives) and or the subject (in intransitives and certain inverse argument combinations in transitives), with a different set of affixes in either case. The table in (17) gives the possible agreement feature bundles in this system, and how they are expressed in the context of different tenses and valencies:

(17) Agreement affixes in active verbal inflections in Traditional Chukchi ${ }^{4}$

\begin{tabular}{|c|c|c|c|c|c|c|c|c|c|}
\hline & \multicolumn{3}{|c|}{ Prefixes } & \multicolumn{6}{|c|}{ Suffixes } \\
\hline$\phi$ & SUBJ.REAL & SUBJ.INT & SUBJ.COND & SUBJ.NFUT & SUBJ.FUT & SUBJ.IRR & OBJ & OBJ (w/ 3sg SUBJ) & OBJ (w/ 2pl SUBJ) \\
\hline $1 \mathrm{sg}$ & $t-$ & $m-$ & $m-^{2}-$ & $-\left(g^{2} e\right) k$ & \multirow{3}{*}{$-\varnothing$} & $-\left(g^{2} e\right) k$ & -gəm & & \\
\hline $1 \mathrm{pl}$ & mot- & $m \partial n-$ & $m \partial n-^{2}-$ & $-m \partial k$ & & $-m \partial k$ & $-m \partial k$ & & \\
\hline $2 \mathrm{sg}$ & \multirow{2}{*}{$\varnothing-$} & \multirow[b]{2}{*}{$q^{-}$} & \multirow{4}{*}{$n-{ }^{?}-$} & $-\left(g^{P}\right) i$ & & $-g i$ & $-g \partial t$ & & \\
\hline $2 \mathrm{pl}$ & & & & $-t ə k$ & $-n-t \partial k$ & $-t \partial k$ & $-t \partial k$ & & \\
\hline $3 \mathrm{sg}$ & \multirow{2}{*}{$(n e-) \emptyset-$} & \multirow{2}{*}{$n-$} & & $-\left(g^{P}\right) i$ & $-\varnothing$ & $-\left(g^{2} e\right) n$ & $-\left(g^{?} e\right) n$ & - nin & \multirow{2}{*}{-tkə } \\
\hline $3 \mathrm{pl}$ & & & & $-\left(g^{P} e\right) t$ & $-\eta \partial-t$ & $-n e t$ & $-n e t$ & -ninet & \\
\hline
\end{tabular}

${ }^{4}$ Prior to the onset of shift, these affixes showed little variation across the dialects investigated in this study 
Every active finite verb in Chukchi draws both a prefix and a suffix from this system (setting aside several other intricacies; a full account of agreement marking is available in Dunn, 1999 and Kantarovich, 2020). Without adopting a particular theoretical framework (aside from assuming the existence of a null morpheme and a certain set of TAM features), it is clear that the active verbal inflectional system has a high degree of descriptive complexity: there are two agreement slots that are filled by different feature bundles, vary according to different conditions, and display asymmetric syncretisms. There is a greater number of possibilities for the suffix slot than the prefix slot; by the same token, the suffix slot contains a greater density of information (tense, mood, and valency in addition to argument agreement). While prefixes are fused with mood, the suffixes redundantly encode tense and mood in addition to their separate slots in the template, but only when agreeing with some subjects (and never when agreeing with the object). Additionally, the last two columns of the table give the portmanteau suffixes in the system, which are used for 3rd person objects only in the context of certain subjects (3sg and 2pl); otherwise, the expected 3rd person object suffixes $\left(-g^{2}\right.$ en or $\left.-n e t\right)$ are used.

We can see that this system is not only complex according to a quantitative Kolmogorov measure, but also according to the three competing principles laid out by Audring (section 1.1.2). The verbal complex as a whole is not very Economical. It encodes three different moods (realis, intentional, conditional), two tenses (future and non-future), and two aspects (neutral and progressive), and does so redundantly in discrete slots in the verbal complex as well as by conditioning the forms of agreement suffixes. The agreement markers themselves are not economical because they encode whether the argument being agreed with is a subject or object, with different forms in either case. The verb also explicitly encodes transitivity via the separate suffixes for transitive vs. intransitive verbs. Thus, the verbal morphology in Chukchi also has an exceptionally high degree of semantic complexity (measured in terms of the density of information in a single word).

This system is also complex according to Audring's Principle of Transparency: there is not always a one-to-one mapping of meaning to form, as there are cases of both fusion (with one slot encoding subject agreement and mood) and multiple exponence (two slots encoding agreement with the subject in certain cases). Individual features (i.e., how they are expressed morphologically) are also not Independent of one another: the expression of subject agreement depends on TAM features, and the expression of object agreement depends on the identity of the subject.

Overall, this system is a prime target for simplification due to language shift, and affords us the opportunity to see how speakers manage these competing types of complexity. Indeed, across the study tasks, shifting speakers of Chukchi consistently use smaller verbal complexes, reducing both the number of distinct slots in the verb as well as the number of morphological possibilities for each slot (resulting in a reduction in allomorphy and the number of morphosemantic features explicitly encoded by the verb). However, these patterns do not necessarily reflect uniform simplification across all possible measures of morphological or featural complexity. They are also regularly accompanied by a trade-off where the same feature or relation is expressed syntactically instead.

\subsubsection{Increased Syncretism in Verbal Inflection vs. Lower Argument Drop Among Shifting Chukchi Speakers}

Shifting Chukchi speakers display a reduction in the number of distinct affixes used in verbal inflection across the picture production task and narratives, but the contrast with conservative speakers is most apparent in the PPE task, where both speaker groups tended to use the same verbs and tenses and where changes to the verbal complex are therefore visible. For pictures that depicted an ongoing (or noncompleted) action, both conservative and shifting speakers frequently opted to use the stative habitual tense, which differs in some ways from the active tense discussed in section 3.2. The stative paradigms only distinguish between two tenses, only have one slot for agreement (a suffix slot), and have one set of suffixes to encode both subject and object agreement. In terms of complexity (as measured by the number of affixes), this is already a simpler verbal complex than that of the active paradigms:

\section{(18) Tense-(Voice or Incorporation)-Stem-Agreement}

However, while this may be a more economical system (fewer slots, fewer encoded features, fewer distinctions per feature), it is not transparent or symmetrical-there is not a one-to-one mapping between form and meaning, as the agreement slot can agree with either the subject or the object (and which argument wins out in transitive verbs is based on a ranking of the person/ number of arguments that cannot be generalized with a single rule). Furthermore, the system preserves a transitivity distinction: rather than by using different suffixes for object vs. subject agreement, transitivity is indicated by the presence of the voice marker ine-, but only in some transitive argument combinations.

With $3>3$ argument combinations (those that were targeted by the picture tasks), the ine- transitivity marker is used by conservative speakers as expected given what we know about the traditional language: it is used in transitive verbs with a $3 \mathrm{sg}$ subject and a 3rd person object (either sg or pl), as in (19).

(19) $3>3$ habitual (stative) inflection produced in the 27PPE task by Chukchi speakers
\begin{tabular}{l|lll|lll} 
& \multicolumn{3}{|c|}{ Conservative speakers $(n=5)$} & \multicolumn{3}{c}{ Shifting speakers $(n=7)$} \\
\hline & Intrans & $3 \mathrm{sgO}$ & $3 \mathrm{plO}$ & Intrans & $3 \mathrm{sgO}$ & $3 \mathrm{plO}$ \\
\hline $3 \mathrm{sgA} / \mathrm{S}$ & $n$ - -qin & $n$-ine- -qin & $n$-ine- -qinet & $n$ - -qin & $n$ - -qin & $n$ - -qin \\
$3 \mathrm{plA} / \mathrm{S}$ & $n$ - -qinet & $n$ - -qin & $n$ - -qinet & $n$ - -qinet & $n$ - -qinet & $n$ - -qinet
\end{tabular}

Meanwhile, when they used the habitual stative tense, shifting speakers uniformly used the system on the right in (19). Compared with the traditional (conservative) system, the shifting system has simpler morphology according to several metrics. In the conservative system, the agreement suffix slot can index either the subject or the object in transitive verbs; simplifying things a bit, the presence of the voice marker ine- generally coincides with subject cross-reference in non-third persons, but also appears in $3 \mathrm{sg}>3 \mathrm{pl}$ combinations, where the suffix slot actually appears to encode the object (-qinet). Otherwise, in third-person combinations, the suffix slot can be analyzed as straightforwardly encoding the object. Looking just at third-person combinations, then, the agreement slot is used for the subject in intransitives and the object in transitives (an absolutively-aligned system). 
In the shifting speakers' system, the agreement slot only ever encodes the subject (an accusatively-aligned system), regardless of the identity of the object, and ine- has been eliminated entirely. The result is a stative verbal complex more like the following:

(20) Tense-Stem-Subject

The elimination of ine- here appears to be a clear-cut case of simplification: a slot and its associated morphology have been removed from the system, so that the resulting system is more Economical (does not encode a transitivity distinction). Whether or not the shift in the agreement slot towards nominative rather than absolutive alignment can be seen as a kind of simplification is less clear, although ergative systems do seem to be less stable crosslinguistically (Nichols 1993; van de Visser 2006), for which some researchers have advanced a processing-based explanation (ergative systems are cognitively more taxing than accusative systems, see Van Everbroeck 2003; Bornkessel-Schlesewsky et al., 2008).

Returning to the active verbal complex introduced in section 3.2, the changes to this system among shifting speakers are far more complicated and variable. In order to probe patterns across the entire agreement systems of these speakers, we elicited full active paradigms in addition to the production tasks. Many could not produce a full paradigm for all subject and object combinations, and no two speakers produced the same paradigms, yet even a single paradigm from a shifting speaker provides evidence that not all morphological change in this population is a straightforward matter of simplification.

The following is a full paradigm for an active non-future neutral transitive verb that was produced by one shifting speaker (this speaker displayed more-or-less the expected patterns for intransitive verbs). A full conservative paradigm is given in (22).

\begin{tabular}{|c|c|c|c|c|c|c|}
\hline & $1 \mathrm{sg} . \mathrm{OBJ}$ & 1pl.oBJ & 2sg.oBJ & 2pl.oBJ & 3sg.OBJ & 3pl.OBJ \\
\hline $1 \mathrm{sg} . \mathrm{SBJ}$ & - & - & $t-l^{2} u-g^{2} e n$ & $t-l^{2} u-t \partial k$ & $t-l^{2} u-g^{2} e n$ & $t-l^{2} u-n e t$ \\
\hline 1pl.sB J & - & - & $m \partial t-l^{2} u-g^{2} e n$ & $m a t-l^{2} u-n e t$ & $m \partial t-l^{2} u-g^{2} e n$ & $m a t-l^{2} u-n e t$ \\
\hline $2 \mathrm{sg} . \mathrm{SBJ}$ & $\emptyset$-ine- $l^{2} u-g^{2} i$ & $\emptyset$-ine-l $l^{2} u-g^{2} e n$ & - & - & $\emptyset-l^{l} u-g^{2} e n$ & $\emptyset-l^{2} u-n e t$ \\
\hline 2pl.sBJ & $\emptyset$-ine- $l^{?} u-t \jmath k$ & $\emptyset$-ine- $l^{2} u-t \partial k$ & - & - & $\emptyset-l^{2} u-t \partial k$ & $\emptyset-l^{2} u-t \partial k$ \\
\hline 3 sg.SBJ & $\emptyset$-ine- $l^{2} u-g^{2} i$ & $\emptyset$-ine-l $l^{2} u-$ ninet & $n e-\emptyset-l^{2} u-g^{P} e t$ & $\varnothing$-ine- $l^{2} u-$ ninet & $\emptyset-l^{?} u-n i n$ & $\emptyset$-l $l^{2} u$-ninet \\
\hline 3pl.sB J & $n e-\emptyset-l^{2} u-g^{2} e n$ & $n e-\emptyset-l^{2} u-m ə k$ & ge-l $l^{2} u-g ə t$ & $n e-\emptyset-l^{2} u-t ə k$ & $n e-\emptyset-l^{2} u-g^{?} e n$ & $n e-\emptyset-l^{2} u-n e t$ \\
\hline
\end{tabular}

(22) Transitive active realis inflection of $l^{?} u$ - 'to see' (conservative system)

\begin{tabular}{|c|c|c|c|c|c|c|}
\hline & 1sg.OBJ & 1pl.OBJ & 2sg.OBJ & 2pl.OBJ & 3sg.OBJ & 3pl.oBJ \\
\hline $\begin{array}{l}1 \mathrm{sg} . \mathrm{SBJ} \\
1 \mathrm{pl} . \mathrm{SBJ}\end{array}$ & - & - & $\begin{array}{l}t-l^{2} u-g \partial t \\
m \partial t-l^{2} u-g \partial t\end{array}$ & $\begin{array}{l}t-l^{2} u-t \partial k \\
m \partial t-l^{2} u-t \partial k\end{array}$ & $\begin{array}{l}t-l^{2} u-g^{2} e n \\
m \partial t-l^{P} u-g^{2} e n\end{array}$ & $\begin{array}{l}t-l^{2} u-n e t \\
m ə t-l^{2} u-n e t\end{array}$ \\
\hline $2 \mathrm{sg} . \mathrm{SBJ}$ & $\emptyset$-ine- $l^{2} u-g^{2} i$ & $\emptyset-l^{2} u-t k u-g^{2} i$ & - & - & $\emptyset-l^{3} u-g^{3} e n$ & $\emptyset-l^{2} u-n e t$ \\
\hline 2pl.sBJ & $\emptyset$-ine- $l^{2} u$-tək & $\emptyset-l^{2} u-t k u-t z k$ & - & - & \multicolumn{2}{|c|}{$\emptyset-l^{2} u-t k \partial$} \\
\hline $\begin{array}{l}3 \mathrm{sg} . \mathrm{SBJ} \\
3 \mathrm{pl} . \mathrm{sBJ}\end{array}$ & $\begin{array}{l}\emptyset \text {-ine-l } l^{2} u-g^{2} i \\
n e-\emptyset-l^{2} u-g \partial m\end{array}$ & $\begin{array}{l}n e-\emptyset-l^{2} u-m ə k \\
n e-\emptyset-l^{2} u-m ə k\end{array}$ & $\begin{array}{l}n e-\emptyset-l^{2} u-g \partial t \\
n e-\emptyset-l^{2} u-g \partial t\end{array}$ & $\begin{array}{l}n e-\emptyset-l^{2} u-t \partial k \\
n e-\emptyset-l^{2} u-t ə k\end{array}$ & $\begin{array}{l}\emptyset-l^{2} u-n i n \\
n e-\emptyset-l^{2} u-g^{?} e n\end{array}$ & $\begin{array}{l}\emptyset-l^{2} u-\text { ninet } \\
\text { ne- } \emptyset-l^{2} u-n e t\end{array}$ \\
\hline
\end{tabular}

The bolded morphemes represent deviations from the expected agreement patterns in the traditional language. First, it is worth noting that a substantial part of the system has not undergone change at all-in particular, the subject agreement prefixes are exactly those we expect in the realis mood. The changes to agreement have been solely to the agreement suffixes-a fact that is not surprising given that the agreement suffix position is multiply complex (high number of possible forms, lack of a one-to-one correspondence between form and function, and dependence on both arguments of the verb in determining the form of the expression of object agreement, as in the portmanteau cases). Still, the nature of these changes is not arbitrary, nor is it a straightforward case of loss (like the loss of the transitivity distinction in the stative habitual tense). Crucially, the suffix agreement slot is preserved; only the distribution of the agreement forms has changed, with $3 \mathrm{rd}$ person object markers spreading to other persons with the same number. Specifically, the 3 sg object suffix, $-g^{2}$ en, occurs for both 1 sg and 2 sg objects and the $3 \mathrm{pl}$ object suffix, $-n e t$, is used in place of the expected $2 \mathrm{pl}$ object form. Interestingly, the $3 \mathrm{pl}$ object portmanteau form that is used only in the context of a $3 \mathrm{sg}$ subject, -ninet, has also spread to other plural arguments, but also only in the context of a 3 sg subject. The resulting neutralizations are color-coordinated in (21).

The changes to the suffixal agreement markers in this speaker's system can be summarized as a neutralization of object encoding in some cases, but with the preservation of a distinction between singular and plural object marking (e.g., the form of the verb when there is a 1 sg subject no longer makes a distinction between whether the object is 2 nd or 3 rd person in the singular, but does in the plural; for 1pl subjects, object person is no longer expressed in either number). In a sense, this can be regarded as a simplification: the person feature has been eliminated in some cases, as have certain forms (such as the 1 sg object agreement suffix, -gam). However, the resulting system is more complex in certain ways. As a whole the system has an added asymmetry, with person-marking of the object occurring in some instances but not others. Additionally, a highly dependent form in the system - the portmanteau suffix -ninet-is the one that has been preserved and has in fact spread to other objects (while seeming to retain the association with 3 sg subjects).

Both types of morphological changes among shifting speakers-those affecting the stative tenses and those affecting the active tenses-have been accompanied by compensatory changes in the syntax. Overall, the changes to the agreement system indicate a shift away from object agreement, which has resulted in a syntactic trade-off: like most polysynthetic languages, traditional Chukchi makes extensive use of argument-drop, especially of pronominal arguments which are already encoded by verbal agreement. Shifting speakers of Chukchi make comparatively less use of pro-drop and have maintained the ergative-absolutive system of case marking on nouns, indicating that the use of overt, case-inflected NPs has emerged as the strategy for expressing the verb's arguments. The strong maintenance of case marking is somewhat unexpected: nominal inflection is often vulnerable in the shift context, especially if it is absent in the contact language (as in the case of Dyirbal, which has lost neutralized any marking of core arguments, likely due to contact with English). While Russian does employ case marking, its core cases are accusatively rather than ergatively aligned; yet most shifting Chukchi speakers have preserved a special agentive case for transitive subjects.

The trade-off between head-marking (agreement) and dependent-marking (case) that has taken place for shifting 
speakers is clear when we consider the following contrastive examples obtained from the controlled narrative tasks:

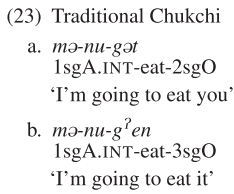

In (24), the speaker has used 3rd person object agreement instead of the expected 2 nd person object agreement, but has compensated for the informational gap by specifying the object as a separate case-marked nominal (which happens to be similar in form to the agreement marker).

\subsubsection{Loss of Productivity vs. Increased Rigidity of Voice Morphology Among Shifting Chukchi Speakers}

Another finding from the combined study tasks was that shifting Chukchi speakers make use of voice morphology (including causatives, applicatives, and noun incorporation) less productively and less frequently than conservative speakers. In the 27PPE task, this is seen most clearly in the occurrence of noun incorporation (or lack thereof). Traditional noun incorporation in Chukchi is syntactic-that is, it is a process whereby an independent noun in the language is combined with an independent verb when the appropriate pragmatic conditions obtain. Typically, a verb incorporates its object in cases where the agent or the event itself is more important than the undergoer (typically when there is an animate subject and an inanimate object). Oblique arguments such as instruments and locations are frequently incorporated as a matter of course; conservative speakers report a strong preference for avoiding the use of multiple free-standing nominals.

Of the 27 stimuli in the task, 12 contained contexts where incorporation of either an object or an oblique was an acceptable strategy for expressing the targeted argument structure of the verb. Four of the conservative speakers produced a total of seven instances of productive incorporation; one of the conservative speakers produced several examples of an incorporative complex for each of the 27 stimuli, including in unexpected scenarios. Within the group of shifting speakers, the five moreexperienced speakers produced a total of four productive instances of incorporation; the youngest generation produced no productive incorporation. While these figures are not wildly different, it is important to note that all but one of the conservative speakers used productive noun incorporation for multiple stimuli; the more experienced shifting speakers who used productive incorporation only did so for one stimulus ('berry-picking', which is a frequent collocation that may be conventionalized for them). In lieu of incorporation, shifting speakers would either supply an alternate lexical item expressing the meaning of the verb plus an argument (usually a denominal verb) or else use the dispreferred strategy among conservative speakers: specifying all arguments as separate case-marked nominals.

Each of these three strategies was employed by three different speakers for one of the stimuli, which featured a woman spreading butter on bread. Conservative speakers produced constructions like the following, where 'butter' (the instrument of spreading according to the target verb's argument structure) was incorporated:

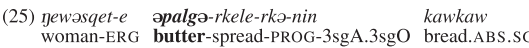

'The woman butter-spreads the bread (spreads butter on the bread)'

An experienced shifting speaker offered a construction using a denominal verb (with 'butter' as the root) instead of incorporation:

(26) newasqet-ne n-ena-para-(a)t-qen kawkaw

woman-ERG.ANIM HAB-TR-butter-VB-3sg bread.ABS.SG

'The woman butters the bread'

Finally, a lower proficiency young speaker produced a sentence with all of the arguments expressed as free-standing nominals, which, unlike (26), is considered highly marked by conservative speakers:

$\begin{array}{llll}\text { (27) njewəsqet-ne } & n \text {-ena-rkele-qen } & \text { kawkawə-tkən-ək } & \text { parapar } \\ \text { woman-ERG.ANIM } & \text { HAB-TR-spread-3sg } & \text { bread-on.top-LOC butter.ABS.SG }\end{array}$

'The woman spreads butter on top of the bread'

As before, it is tempting to refer to this kind of reduction in usage as simplification because of a loss of productivity. However, while the productivity of the process has been reduced, judgments about appropriate uses of incorporation are maintained even among the lowest proficiency speakers. Following their participation in the production task, speakers were explicitly asked about the possibility of incorporation for the transitive stimuli in the task. Both conservative speakers and shifting speakers unanimously rejected the incorporation of animate arguments, although they differed as to which inanimate arguments could be incorporated (with conservative speakers allowing for more incorporation than shifting speakers). Thus, the loss of productivity can actually be interpreted as an increase in the arbitrariness of the system, since only certain lexical items can be incorporated. In turn, the rule accounting for this process is more complex: rather than allowing for the incorporation of any inanimate noun, the acceptable incorporees (and any generalizations about them) must be enumerated individually.

Furthermore, as with the decline of object agreement marking, the avoidance of incorporation is instead offloaded onto the syntax, as speakers still find a way to express the argument. The alternative, which we can see in (27), is the use of a separate NP which must be marked with the appropriate case, which in and of itself is a morphologically complex phenomenon in Chukchi (due to the existence of different noun classes, which shifting speakers also maintain). In fact, the appending of a bare nominal stem to the verb is in some sense a morphologically simpler alternative: since the noun does not receive case-marking, the speaker does not need to 
access knowledge about its grammatical role (since both objects and obliques can be incorporated) or its noun class. Nevertheless, this is a strategy that shifting speakers are avoiding.

\section{DISCUSSION: RETHINKING COMPLEXITY IN SHIFTING LANGUAGES}

The present study of shifting speakers' morphosyntactic patterns in two typologically-distinct languages (Even, a head-final agglutinating language, and Chukchi, a polysynthetic language with free word order) reveals that claims about simplification in shift have been overblown. We have considered two separate systems of argument encoding-verbal agreement and incorporation in Chukchi and case marking in Even-and have shown how shifting speakers of either language do not merely lose features of the standard language. In both cases, speakers have largely retained the grammatical rules governing the relevant patterns, even if they use them to a lesser extent than proficient speakers. Chukchi speakers continue to make use of two agreement slots, even as they have repurposed the role of the suffix agreement slot. Similarly, they retain pragmatic rules governing when noun incorporation is appropriate, but simply use the structure less frequently. By the same token, most Even speakers have not entirely lost the preference for $\mathrm{V}$-final order, and with the exception of the lowest proficiency speakers, they have also retained case marking.

By and large, shifting speakers differ from proficient speakers not in the relative complexity of their systems, but how they make use of existing resources in the languages: as one domain of their systems changes, a compensatory change (or "trade-off") occurs elsewhere. Shifting speakers of Chukchi have transitioned from a system in which the verb is the primary locus of core-argument encoding (through subject and object agreement and noun incorporation) to a system where the existing case-marked NPs in the language are no longer optional (cannot be dropped). Shifting speakers of Even have adopted a distinctive word order (different from the one that is expected in Standard Even) to signal argument encoding.

It should also be noted that the changes that have taken place in either language cannot be unilaterally attributed to contact influence from Russian, as is often assumed in language shift. Direct interference from Russian is just one factor influencing speaker behaviors in the shift setting, but these systems have not necessarily evolved to be like their Russian counterparts. For example, most Chukchi speakers maintain ergative-absolutive case marking and free word order, unlike Russian's nominativeaccusative system and preference for SVO in unmarked contexts. Some Even speakers make use of no case marking at all (not a Russian-like pattern) and have started using SOV order more rigidly, rather than less. Ultimately, any reduction of inflectional morphology in Even and Chukchi that targets features that happen to be absent in Russian cannot be uniquely attributed to Russian influence, as opposed to the trends we see in general in language obsolescence (see Kantarovich 2020, ch. 6 for further discussion). Instead, we see the same sorts of changes happening in tandem that we find in languages not actively under contactbased influence: those that stem from complexity trade-offs between different levels of the grammar.
These findings have implications for studies of complexity tradeoffs more generally. Word order is known to interact with certain morphosyntactic features; of these the most relevant for the current study is the case marking system. It is well-known in the typology literature that there is a (non-perfect) correlation between the constituent order flexibility and the presence of the case marking system in a language, such that languages with more flexible constituent order also tend to use morphological case marking to signal grammatical function assignment, suggesting a complexity trade-off between constituent order flexibility and case marking (Sinnemäki, 2014). Mirroring the typological patterns, a number of language processing and artificial language learning studies found that language learners (and users) are biased against excessive redundancy of grammatical encoding-more case marking is produced (and therefore more production effort) only when it carries the benefit to reduce uncertainty of the intended message, suggesting the observed typological correlation between constituent order and case marking is at least partly the output of a learning process that is sensitive to the trade-off between processing effort and communication success (Kurumada and Jaeger, 2015; Fedzechkina et al., 2017; Fedzechkina and Jaeger, 2020). All together, this body of research suggests the investigation of constituent order change should not proceed without also carefully considering the potential simultaneous changes in morphology, especially case marking.

Moreover, many studies of complexity trade-offs (specifically between word and constituent order and case marking) have been conducted using artificial miniature languages (see e.g., Fedzechkina and Jaeger, 2020, among others, for a recent overview). These studies have enabled generalizations based on a small sample lexicon with a small number of constructions. In actual, living languages, the possible lexical inventory is considerably larger, as are the syntactic options available to speakers. In addition, information structure plays a role in word order in many languages, and the contexts in which laboratory studies are produced are highly constrained.

There are several advantages to the use of the methodology in the PPE tasks. Most obviously, supplying the lexicon results in directly comparable responses across speakers. But there are clear advantages for this methodology in working with less proficient speakers. First, even those who do not command inflectional morphology can create sentences of a type relying on word order. Second, even the more proficient L2 speakers have gaps in their production, and yet are tightly constrained by the lexicon they are required to use. That is, the experiment forces them to utter sentences that they might avoid if speaking more freely. As a result, we are able to more deeply probe the systems of less-proficient speakers, and test not only what features they continue to use but also those that are infrequent in their speech, but about which they maintain intuitions.

This paper follows a long tradition in the literature on complexity in arguing: complexity is complex. While this seems like an obvious claim, it is one that has not often been advanced in studies of obsolescing languages; if anything, studies of these languages have tended to underrepresent the complexity that persists in the systems of shifting speakers, choosing instead to focus on subtractive simplification (i.e., the loss of specific morphological features). We have sought to demonstrate here that while subtractive 
simplification is indeed a hallmark characteristic of language shift, it is by no means the most enlightening when it comes to understanding these speakers' linguistic capabilities. While we do not advocate for a new theoretical approach to complexity (or seek to undermine discussions of complexity in language contact, which can be worthwhile), we hope this paper highlights the need for a more nuanced treatment of simplification in language shift.

\section{DATA AVAILABILITY STATEMENT}

The raw data supporting the conclusion of this article will be made available by the authors, without undue reservation.

\section{ETHICS STATEMENT}

The studies involving human participants were reviewed and approved by The Institutional Review Board of the University of Chicago. Written informed consent for participation was not required for this study in accordance with the national legislation and the institutional requirements.

\section{AUTHOR CONTRIBUTIONS}

JK and LG: conception and design of study. JK, LG, and AV: data collection. JK, LG, AV, and EN: data processing and analysis, with JK primarily responsible for Chukchi and LG,

\section{REFERENCES}

Aitchison, J. (1991). Language Change: Progress or Decay? Cambridge: Cambridge University Press.

Audring, J. (2017). Calibrating Complexity: How Complex Is a Gender System? Lang. Sci. 60, 53-68. doi:10.1016/j.langsci.2016.09.003

Bakker, P., Daval-Markussen, A., Parkvall, M., and Plag, I. (2013). "Creoles Are Typologically Distinct from Non-creoles," in Creole Languages and Linguistic Typology. Editors P. Bhatt and T. Veenstra (Amsterdam: John Benjamins), 9-45. doi:10.1075/bct.57.02bak

Bickel, B., Comrie, B., and Haspelmath, M. (2015). Leipzig Glossing Rules. Leipzig, Germany: Department of Linguistics of the Max Planck Institute for Evolutionary Anthropology and the Department of Linguistics of the University of Leipzig.

Blasi, D. E., Michaelis, S. M., and Haspelmath, M. (2017). Grammars Are Robustly Transmitted Even during the Emergence of Creole Languages. Nat. Hum. Behav. 1, 723-729. doi:10.1038/s41562-017-0192-4

Bobaljik, J. D. (1998). Pseudo-ergativity in Chukotko-Kamchatkan Agreement Systems. Recherches Linguistiques de Vincennes 27, 21-44.

Bornkessel-Schlesewsky, I., Choudhary, K. K., Witzlack-Makarevich, A., and Bickel, B. (2008). Bridging the gap between Processing Preferences and Typological Distributions: Initial Evidence from the Online Comprehension of Control Constructions in Hindi. Scales (Linguist. Arbeits Berichte) 86, 397-436. doi:10.5167/uzh-76736

Campbell, L., and Muntzel, M. C. (1989). "The Structural Consequences of Language Death," in Investigating Obsolescence: Studies in Language Contraction and Death. Editor N. Dorian (Cambridge: Cambridge University Press), 181-196. doi:10.1017/cbo9780511620997.016

Dahl, O. (2004). The Growth and Maintenance of Linguistic Complexity. Amsterdam: John Benjamins.
$\mathrm{AV}$, and EN responsible for Even. JK and LG: main responsibility for drafting the manuscript. Both AV and EN contributed to the article and provided critical revision of the manuscript.

\section{FUNDING}

Research was funded by NSF-BCS \#761551, Investigating language contact and shift through experimentallyoriented documentation (data collection and processing) and Megagrant \#2020-220-08-6030 from the Russian Federation, for the project Preservation of Linguistic and Cultural Diversity and Sustainable Development of the Arctic and Subarctic of the Russian Federation (data processing and analysis, results).

\section{ACKNOWLEDGMENTS}

We would like to thank our many colleagues who have helped shape our thinking and contributed to our understanding of these languages and questions, at the North-Eastern Federal University in Yakutsk, the Institute for Humanities Research and Indigenous Studies of the North of the Siberian Branch of the Russian Academy of Sciences in Yakutsk, and the Institute for Linguistic Studies, Russian Academy of Sciences in St. Petersburg. Any errors are solely our own.

de Groot, C. (2008). "Morphological Complexity as a Parameter of Linguistic Typology: Hungarian as a Contact Language," in Language Complexity: Typology, Contact, and Change. Editors M. Miestamo, K. Sinnemäki, and F. Karlsson (Amsterdam: John Benjamins), 191-215. doi:10.1075/ slcs.94.13gro

Dorian, N. C. (1977). The Problem of the Semi-speaker in Language Death. Linguistics 15, 23-32. doi:10.1515/ling.1977.15.191.23

Dorian, N. C. (1981). Language Death: The Life Cycle of a Scottish Gaelic Dialect. Philadelphia: University of Pennsylvania Press.

N. C. Dorian (1989). Investigating Obsolescence: Studies in Language Contraction and Death (Cambridge: Cambridge University Press).

Dryer, M. S. (2013). "Order of Subject, Object and Verb," in The World Atlas of Language Structures Online. Editors M. S. Dryer and M. Haspelmath (Leipzig: Max Planck Institute for Evolutionary Anthropology).

Dunn, M. (1999). A Grammar of Chukchi. Canberra: Australian National University. Ph.D. thesis.

Fedzechkina, M., and Jaeger, T. F. (2020). Production Efficiency Can Cause Grammatical Change: Learners Deviate from the Input to Better Balance Efficiency against Robust Message Transmission. Cognition 196, 104115. doi:10.1016/j.cognition.2019.104115

Fedzechkina, M., Newport, E. L., and Jaeger, T. F. (2017). Balancing Effort and Information Transmission during Language Acquisition: Evidence from Word Order and Case Marking. Cogn. Sci. 41, 416-446. doi:10.1111/cogs.12346

Gibson, E., Futrell, R., Piantadosi, S. P., Dautriche, I., Mahowald, K., and Bergen, L. (2019). How Efficiency Shapes Human Language. Trends Cogn. Sci. 23, $389-$ 407. doi:10.1016/j.tics.2019.02.003

Good, J. (2012). Typologizing Grammatical Complexities: or Why Creoles May Be Paradigmatically Simple but Syntagmatically Average. J. Pidgin Creole Languages 27, 1-47. doi:10.1075/jpcl.27.1.01goo 
Grenoble, L. A. (2000). "Morphosyntactic Change: The Impact of Russian on Evenki," in Languages in Contact. Editors D. Gilbers, J. Nerbonne, and J. Schaeken (Amsterdam: Rodopi), 105-120.

Hawkins, J. A. (2004). Efficiency and Complexity in Grammars. Oxford: Oxford University Press.

Kantarovich, J. (2020). Argument Structure in Language Shift: Morphosyntactic Variation and Grammatical Resilience in Modern Chukchi. Chicago: University of Chicago. Ph.D. thesis.

Klein, T. B. (2012). Creole Phonology Typology: Phoneme Inventory Size, Vowel Quality Distinctions and Stop Consonant Series. In The Structure of Creole Words, eds. P. Bhatt and I. Plag (Tübingen: Max Niemeyer Verlag). 3-22. doi:10.1515/9783110891683.3

Koplenig, A., Meyer, P., Wolfer, S., and Müller-Spitzer, C. (2017). The Statistical Trade-Off between Word Order and Word Structure - Large-Scale Evidence for the Principle of Least Effort. PLoS One 12, e0173614. doi:10.1371/ journal.pone.01736110.1371/journal.pone.0173614

Kurumada, C., and Jaeger, T. F. (2015). Communicative Efficiency in Language Production: Optional Case-Marking in Japanese. J. Mem. Lang. 83, 152 - 178. doi:10.1016/j.jml.2015.03.003

Kusters, W. (2008). "Complexity in Linguistic Theory, Language Learning and Language Change," in Language Complexity: Typology, Contact, and Change. Editors M. Miestamo, K. Sinnemäki, and F. Karlsson (Amsterdam: John Benjamins), 3-22. doi:10.1075/slcs.94.03kus

Malchukov, A. L. (1995). Even. Languages Of the World/Materials 12. Munich: Lincom.

Malchukov, A. L. (2003). "Russian Interference in Tungusic Languages in an Areal Typological Perspective," in Convergence and Divergence of European Languages. Editor P. S. Ureland (Berlin: Logos Verlag Berlin GmbH), 235-249.

McWhorter, J. (2001). The World's Simplest Grammars Are Creole Grammars. Linguist. Typology, 125-165. doi:10.1515/lity.2001.001

Meakins, F., and Pensalfini, R. (2016). "Gender Bender: Superclassing in Jingulu Gender Marking," in Loss and Renewal: Australian Languages since Colonisation. Editors F. Meakins and C. O'Shannessy (Berlin/Boston: De Gruyter Mouton), 425-450.

Meakins, F., Hua, X., Algy, C., and Bromham, L. (2019). Birth of a Contact Language Did Not Favor Simplification. Language 95, 294-332. doi:10.1353/lan.2019.0032

Miestamo, M. (2008). "Grammatical Complexity in a Cross-Linguistic Perspective," in Language Complexity: Typology, Contact, and Change. Editors M. Miestamo, K. Sinnemäki, and F. Karlsson (Amsterdam: John Benjamins), 23-41. doi:10.1075/slcs.94.04mie

Mufwene, S. S., Coupé, C., and Pellegrino, F. (2017). “Complexity in Language: A Multifaceted Phenomenon," in Complexity in Language: Developmental and Evolutionary Perspectives. Editors S. S. Mufwene, C. Coupé, and F. Pellegrino (Cambridge: Cambridge University Press), 1-29.

Muysken, P. (2000). Bilingual Speech: A Typology of Code-Mixing. Cambridge: Cambridge University Press.

Nedjalkov, V. P. (1977). “Posessivnost' I Inkorporatsija V Chukotskom Jazyke (Inkorporatsija Podlezhashchego) [Possessivity and Incorporation in Chukchi (Incorporation of Subject)]," in Problemy Lingvisticheskoj Tipologii I Struktury Jazyka. Editor V. S. Khrakovskij (Leningrad: Nauka), 108-138.

Nichols, J. (1993). Ergativity and Linguistic Geography. Aust. J. Linguist. 13, 39-89. doi:10.1080/07268609308599489

O'Shannessy, C. (2011). “Language Contact and Change in Endangered Languages," in The Cambridge Handbook of Endangered Languages. Editors P. K. Austin and J. Sallabank (Cambridge University Press), 78-99.

Plag, I. (2003). "Introduction: The Morphology of Creole Languages," in Yeark Book of Morphology 2002. Editors G. Booij and J. van Marle (Alphen aan den Rijn, Netherlands: Kluwer), 1-2. doi:10.1007/0-306-48223-1_1
Polinskaja, M. S., and Nedjalkov, V. P. (1987). Contrasting the Absolutive in Chukchee: Syntax, Semantics, and Pragmatics. Lingua 71, 239-269. doi:10.1016/0024-3841(87)90074-x

Polinskaja, M. S. (1991). "Inkorporirovannoe Slovo V Chukotskom Jazyke [Incorporated Word in Chukchi]," in Morfema I Problemy Tipologii. Editor I. F. Vardul (Moscow: Nauka), 357-382.

Polinsky, M. (2018). Heritage Languages and Their Speakers. Cambridge: Cambridge University Press.

Rishes, L. D. (1947). Armanskij Dialekt Èvenskogo Jazyka [The Arman Dialect of the Even Language]. Leningrad: Institute of Linguistics, Academy of Sciences of the USSR. Ph.D. thesis.

Robbek, V. A. (1989). Jazyk Èvenov Berezovki. [The Language of the Even of Berezovka. Leningrad: Nauka.

Sasse, H.-J. (2001). “Typological Changes in Language Obsolescence," in Language Typology and Language Universals: An International Handbook. Editor M. Haspelmath (Berlin, Germany: Walter de Gruyter), 1668-1677. doi:10.1515/9783110171549.2.15.1668

Schmidt, A. (1985). Young People's Dyribal. Cambridge: Cambridge University Press.

Siewierska, A. (1998). "Variation in Major Constituent Order: A Global and a European Perspective," in Constituent Order in the Languages of Europe: Empirical Approaches to Language Typology. Editor A. Siewierska (Berlin: Mouton de Gruyter), 475-551. doi:10.1515/9783110812206.475

Sinnemäki, K. (2014). "Complexity Trade-Offs: A Case Study,” in Measuring Grammatical Complexity. Editors F. J. Newmeyer and L. B. Preston (Oxford: Oxford University Press), 179-201. doi:10.1093/acprof:oso/9780199685301.003.0009

Skorik, P. J. (1948). Ocherki Po Sintaksisu Chukotskogo Jazyka [Essays on the Syntax of the Chukchi Language. Leningrad: Uchpedgiz. Ph.D. thesis.

Spencer, A. (1996). Agreement Morphology in Chukotkan. Essex Res. Rep. Linguist. 10, 1-34. doi:10.1016/s0269-915x(96)80077-2

Trudgill, P. (2011). Sociolinguistic Typology: Social Determinants of Linguistic Complexity. Oxford: Oxford University Press.

van de Visser, M. (2006). The Marked Status of Ergativity. Amsterdam: LOT Publications.

van den Bos, J., Meakins, F., and Algy, C. (2017). Searching for "Agent Zero": The Origins of a Relative Case. Lang. Ecol. 1, 4-24. doi:10.1075/le.1.1.02van

Van Everbroeck, E. (2003). Language Type Frequency and Learnability from a Connectionist Perspective. Linguist. Typology 7, 1-50. doi:10.1515/lity.2003.011

Weyerts, H., Penke, M., Münte, T. F., Heinze, H.-J., and Clahsen, H. (2002). Word Order in Sentence Processing: An Experimental Study of Verb Placement in German. J. Psycholinguistic Res. 31, 211-268. doi:10.1023/A: 1015588012457

Conflict of Interest: The authors declare that the research was conducted in the absence of any commercial or financial relationships that could be construed as a potential conflict of interest.

Publisher's Note: All claims expressed in this article are solely those of the authors and do not necessarily represent those of their affiliated organizations, or those of the publisher, the editors and the reviewers. Any product that may be evaluated in this article, or claim that may be made by its manufacturer, is not guaranteed or endorsed by the publisher.

Copyright (c) 2021 Kantarovich, Grenoble, Vinokurova and Nesterova. This is an open-access article distributed under the terms of the Creative Commons Attribution License (CC BY). The use, distribution or reproduction in other forums is permitted, provided the original author(s) and the copyright owner(s) are credited and that the original publication in this journal is cited, in accordance with accepted academic practice. No use, distribution or reproduction is permitted which does not comply with these terms. 